\title{
correspondence
}

\section{Soviet dissenters in need of help}

SIR,--The case of Vladimir Bukovsky (February 6) highlights a disturbing aspect involving my own profession. Bukovsky was released from a labour camp in 1970 after several spells of 'treatment' for his dissenting views. He spent the next 14 months of liberty collecting evidence of psychiatric abuses for the suppression of political dissent in the Soviet Union at great risk to himself. His only hope of protection lay in the forthcoming Congress of the World Psychiatric Association (WPA) in Mexico City in 1971. It was to psychiatrists in the West, and to the psychiatrists attending this congress in particular, that Bukovsky sent his covering letter in the form of an appeal when he sent the documents out to the West. Their authenticity has never been questioned. The Executive Committee of the World Psychiatric Association declined, however, to allow discussion of this problem despite the efforts of some psychiatrists. This shameful act of betrayal produced a savage reprisal in the form of a 12-year prison sentence and the terrible conditions under which Bukovsky has to exist. It is not a story that a psychiatrist can tell with pride.

We now have information that the Soviet authorities were extremely apprehensive about the Mexican Congress. At the time Mr Victor Fainberg, a dissenter, was in a Leningrad psychiatric prison hospital, from where he has now succeeded in emigrating to Israel. He tells me that he and his friend Borisov made certain demands for improving the conditions of the inmates of the hospital and for a re-examination of their own cases by the Court. Prior to the Mexico Congress conditions improved and the Soviet authorities agreed to have the cases re-examined. As soon as the decision of the Executive Committee of the World Psychiatric Association became known, conditions became worse than they had ever been and their request for reexamination by the Courts was dismissed with a contemptuous laugh. It can be assumed that in other special hospitals the same thing occurred. The failure of the WPA to rally to the defence of Bukovsky and the other 'lunatic' dissidents was an act of opportunism and devoid of all compassion.

I am writing to urge psychiatrists to do all they can to right a terrible wrong

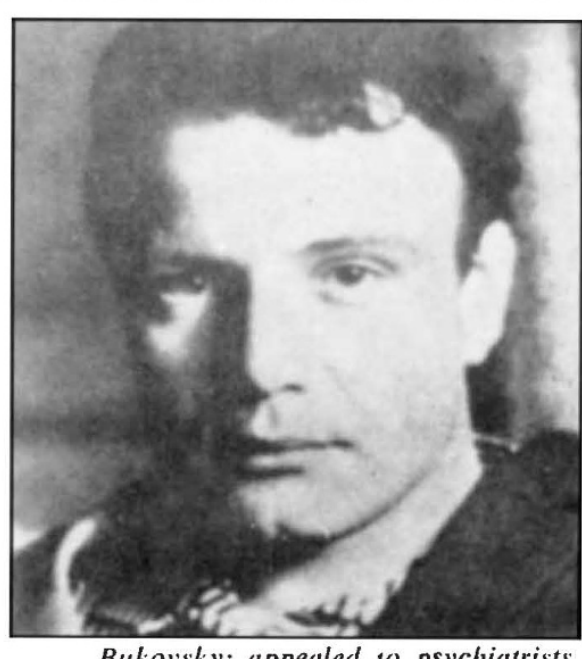

Bukovsky: appealed to psychiatrists

that has been committed and to put all possible pressure, both individually and through their associations, on their Soviet colleagues and Soviet authorities to secure the release of a brave and generous man.

To move to the case of another dissident whose case has been mentioned in Nature recently, I can report that I have been asked by Mrs Plyushch to act as psychiatrist in an investigation into her husband's psychiatric state. This is in connection with legal action which she intends to bring against the Dniepropetrovsk special hospital for unlawful detention and criminal negligence in his treatment at that hospital.

Leonid Plyushch was sentenced to detention in a special hospital after examination by three psychiatric commissions, one of which pronounced him sane. The final one, presided over by Professor Snezhnevsky considered him as suffering from schizophrenia and stated that he had 'delusions of inventions', a reference presumably to Plyushch's interest in games theories, which he shares with his wife.

The case was heard in camera at Kiev and a large number of infringements of Soviet law appear to have been committed. Thus, defence counsel was not granted time for a proper interview and was told by the Judge to base his defence on evidence contained in the prosecutor's files.

A collection of Plyushch's letters has been published in Russian by the Herzen Press in Amsterdam. The first letter was written just after his arrest and the others after his incarceration in the Dniepropetrovsk special hospital, one of the most feared in the Soviet
Union. The letters show a lively, highly intelligent and understanding man for whom the experiences in the hospital were shattering. They show no indication whatsoever of mental illness.

According to information received only last week the 'treatment' received by Plyushch has reduced him to a state of complete nervous collapse so that proper psychiatric treatment under proper humane conditions might really be indicated at the present time.

I am prepared at any time to act as a psychiatrist representing the Plyushch family and would examine $\mathrm{Mr}$ Plyushch either at Dniepropetrovsk special hospital, or preferably for all concerned, in a hospital in the UK. Should Mrs Plyushch's application for emigration to the West for her husband, herself and two children be granted, I would be prepared to participate in any therapeutic measures that might be considered necessary to restore him to his previous good health.

G. A. Low BEER

Consultant Psychiatrist,

Horton Hospital,

Epsom, UK

\section{Hungarian visas}

Sir,- - On behalf of the Presidency of the Hungarian Biochemical Society and also in the name of those who made considerable efforts to ensure the successful organisation of the ninth FEBS Meeting in Budapest in 1974, allow me to express my profound disapproval of the letter entitled. "Entry forbidden" (December 13, 1974) that was written and sent to me as a New Year's present by Ms Peller.

I firmly believe that you are well aware of the fact that the Ninth FEBS Meeting was a success, and it served well not only the exchange of scientific information, but also international scientific cooperation and collaboration. May I quote a part from the letter of Professor H. R. V. Arnstein, SecretaryGeneral of FEBS, addressed to Academician T. Erdey-Gruz, President of the Hungarian Academy of Sciences? "The organisation and scientific standard of the Budapest Meeting were excellent and I have heard many favourable comments. I am sure that the meeting will long be remembered with pleasure by all the biochemists who were fortunate enough to take part and it will have contributed significantly to scientific cooperation in Europe both now and in the future". Similar appre- 
ciations were also received from a number of participants from all over the world.

It is incomprehensible to us why such real and true information about the ninth FEBS Congress did not appear in your journal. We think this would have indeed served international scientific relationships well.

Regarding Ms Peller's visa, the facts can be summarised briefly as follows. Ms Peller's request for a visa arrived in Budapest very late. In spite of this it was dealt with and the visa sent to Vienna, just as were a number of other visas of members of the Israeli Biochemical Society. Ms Peller arrived in Vienna a few days before her visa came through and she had not the patience to wait for it; the visa was left at the Hungarian Embassy in Vienna. I would like to mention that more than 2,000 active members from 38 countries participated in this congress and everybody who arranged their visa in due time was able to enter Hungary.

\section{Secretary of the Hungarian}

Daniel BagdY

Biochemical Society

\section{Nutritional research}

SIR,-The very real issue which concerns both John Rivers (January 10) and John Yudkin (January 31) in their recent correspondence on the Neuberger report is the balance which must be maintained between applied nutritional research into topics of human and social concern and the more basic type of research usually associated with nutritional biochemistry. There is risk, however, that the intensity of their criticism might lead the non-nutritionist to believe that the policy makers, particularly those associated with the Medical Research Council (MRC), have shown little concern over this matter. This would be far from true and it is to correct this possible misconception that we are writing this letter.

In 1971 an MRC subcommittee, of which incidentally Professor Neuberger was a member, recommended a change in policy at the Dunn Nutritional Laboratory and this was subsequently approved by the council as follows: "The council recognise the need to lay foundations for more research designed to investigate specific nutritional problems both in the United Kingdom and overseas and they have agreed that in the future research programme of the laboratory there should be a change in emphasis from basic biochemistry towards applied nutritional studies, in particular clinical and epidemiological investigations. Biochemical research will continue in close relation with applied studies".

This policy statement became the basis of our present research pro- gramme, all of which is related directly to a specific human or clinical problem. These studies have, however, to rely heavily on a firm backing of fundamental research, for in all too many nutritional disorders we lack the basic information to mount really effective applied programmes. Obesity is a good example. We just do not know why individual people lay down different amounts of fat on apparently similar energy intakes and expenditures. At the Dunn, obesity is being investigated on a broad front, using a whole-body calorimeter together with epidemiological studies into the functional significance of different degrees of obesity in terms of morbidity and exercise potential and metabolic studies on the relative economics of different enzyme pathways.

There is considerable interest concerning the role of dietary fibre and this, too, is the subject for a bivalent approach, defining more accurately the metabolic functions of the unavailable carbohydrates and quantitifying, by epidemiological and clinical investigations, the practical benefits or disadvantages which might accrue from increasing the fibre content of the diet.

There is also concern about the nutritional status of elderly people, especially those living alone. Recent evidence has suggested the possible existence of subclinical riboflavin and vitamin $\mathrm{C}$ deficiencies, but in our present state of knowledge we do not know the real significance of the findings. Again, we have an epidemiological investigation under way to reveal the environmental and sociological factors which are causing these abnormalities, linked with laboratory research to define what they mean. Only in this way can we plan effective action should this prove necessary.

Bone disorders are also a problem of the aged and the role of vitamin $D$ in these is likewise under intensive study.

These are just a few of the community-oriented research projects in the UK and overseas in which we are involved and in which we are trying to achieve the same sort of scientific balance.

It is perhaps unfortunate that on first appraisal the Neuberger report does seem to contain more on biochemistry than on 'social' nutrition, but closer scrutiny will show that it quite specifically states that there is a need for more research in this area as well as on other aspects of human and clinical nutrition. The positive point which comes out of the report and the criticisms it has invoked is that nutritional science is very much alive and of importance, not just in an international context but for the health and welfare of people in the UK as well. Nutrition has to be a broadly based science and it is up to nutritional scientists to make certain their subject is able to develop along balanced lines. This is what the debate should be all about.

R. G. WhiteheAd

W. P. T. J JMES

Dunn Nutritional Laboratory,

Cambridge, UK

S!R,-As a nutritionist who worked for more than 10 years in the Nutrition Division of the Food and Agriculture Organisation of the United Nations, I feel I must take issue with several statements in the Joint ARC/MRC Report on Food and Nutrition Research.

I strongly support those who have already expressed the view that the Report is excessively biased towards the cellular and subcellular level of nutrient activity, and virtually ignores the fact that nutrition is concerned primarily with the food that people eat. The opportunity has been missed for stressing the inseparable interrelationships between agriculture and nutrition, both quantitatively and qualitatively. Thus one question that urgently needs answering is whether this country can increase its food production beyond the present level that meets only about half of our consumption, and in particular how in doing so it can make the most useful contribution to human natrition? Such a possibility of collaboration between the two Research Councils is not mentioned.

I am one of those nutritionists who have long believed that, however much research still needs to be done in such areas as the effects of nutrients on metabolism, we already know enough to seek to apply our present knowledge to large scale improvements in the health in our own country and in the rest of the world. But to do this, we need a far more aggressive attack on the problem of how to affect people's eating habits than the lukewarm attitude indicated in the report by such statements as: "On the evidence of published literature, the effect of advertising on food consumption patterns appears not to have been studied," or "It may also be desirable to find ways of changing patterns of food consumption when supplies are limited." Do we need another war, or a series of world food crises, to persuade us that this is a problem crying out for research?

In considering training for research in nutrition, the Committee has clearly not surveyed the facts, for it says that it considers that first degrees in nutrition and food science "make relatively little contribution to research potential." This is simply not true. In my work with FAO, I have for example met graduates in nutrition from Queen Elizabeth College carrying out research 